\title{
Alterações metabólicas em células de glioblastoma expostas a piriproxifeno
}

\author{
Karen Noda Morishita*, Estela de Oliveira Lima, Marcelo Lancellotti, Diego Andreazzi Duarte, Carlos Fernando \\ Odir de Melo, Mohamed Ziad Dabaja, Diogo Noin de Oliveira, Tatiane Melina Guerreiro, Jeany Delafiori, Flávia \\ Luísa Dias-Audibert, Rodrigo Ramos Catharino.
}

\begin{abstract}
Resumo
O piriproxifeno é um inseticida utilizado como estratégia de combate ao mosquito do gênero Aedes e contra pragas em diversas culturas agrícolas. Existem alguns estudos que demonstram que o pesticida tem efeito antiproliferativo em cérebro de mamíferos, além de ser um agonista de PPARy, mecanismo recentemente explorado para combate ao câncer. Dessa forma buscou-se elucidar possíveis marcadores que indiquem o mecanismo de ação do piriproxifeno sobre o glioblastoma. Verificou-se que há mudanças no metabolismo lipídico das células, o que também ocorre quando o pesticida é associado ao Zika vírus, que, por sua vez, já demonstrou ter efeito citopático em células de glioblastoma.
\end{abstract}

\section{Palavras-chave:}

Piriproxifeno, Zika vírus, glioblastoma.

\section{Introdução}

O piriproxifeno, inseticida de fórmula estrutural similar ao do ácido retinoico, pode ter efeito negativo em proliferação ou manutenção de células do tecido neural de mamíferos [1].

Holmes (2016) [2] demonstrou que o piriproxifeno pode ativar receptores ativados por proliferador de peroxissomo (PPARy) que são responsáveis pela homeostase de lipídios e glicose quando dimerizam com RXRs e que podem interferir na via de mTOR.

Os agonistas de PPARy vêm sendo amplamente estudados como potenciais fármacos para o tratamento do câncer.

Estudos realizados por Lima et al. (2017) [3] indicaram o Zika vírus como uma estratégia para tratar o glioblastoma, o tipo histológico de glioma mais agressivo. Além do efeito citopático, o vírus também demonstrou possuir ação na inibição da via de mTOR [4].

Por isso, buscou-se avaliar metabólitos de células de glioblastoma expostos tanto ao pesticida quanto à associação do Zika vírus com o piriproxifeno. $O$ vírus forneceria o processo de tropismo da terapia às células neurais, além da citotoxicidade, e 0 pesticida potencializaria o efeito antiproliferativo sobre as células cancerígenas.

\section{Resultados e Discussão}

A análise metabolômica foi realizada a partir da espectrometria de massas de alta resolução com ionização por eletrospray. Os dados de $m / z$ e intensidades foram submetidos à análise estatística de PLS-DA (Partial least squares regression - Discriminant Analysis) para definir as $\mathrm{m} / \mathrm{z}$ capazes de discriminar os tratamentos do controle. A estrutura das moléculas foi sugerida a partir de busca na base de dados Metlin. Os marcadores sugeridos na comparação entre teste controle versus pesticida e entre teste controle versus pesticida com Zika eram bastante semelhantes.

A fosfatidilcolina (PC), o principal lipídio de membrana celular, foi encontrado como um possível biomarcador de ambos os tratamentos de células de glioblastoma.

Como o tratamento das células de glioblastoma com pesticida causaram um aumento nos níveis de PC, a enzima CTP:fosfocolina-citidiltransferase (CCT) deve ter aumentado sua ação.

O aumento de atividade de CCT aumenta o consumo e diminui os níveis de fosfocolina que é mitogênica e promove tumorigênese, o que pode indicar um efeito positivo na ação antiproliferativa de células U251.

Similarmente, Marcucci et al. (2010) [5] demonstraram que a diferenciação de neurônios induzida por ácido retinoico apresenta síntese de PC por aumento na atividade de CCT.

Nas células, exceto em células do cérebro normais, TG podem ser estocados em gotas de lipídio nas células. Interessantemente, gotas de lipídio podem ser encontradas em gliomas mais graves [6] e as análises realizadas indicam possível consumo de TG nos tratamentos realizados.

\section{Conclusões}

A partir dos experimentos realizados, verificou-se que o pesticida sozinho ou associado ao Zika vírus são capazes de causar alterações importantes nas vias lipídicas de células de glioblastoma humano quando visase diminuir os efeitos proliferativos.

\section{Agradecimentos}

PIBIC - CNPq e Professora Doutora Patricia Prediger.

[1] Parens, R.; Nijhout, H.F.; Morales, A.; Costa, F. X.; Bar-Yam, Y. A Possible Link Between Pyriproxyfen and Microcephaly. PLOS Currents Outbreaks, Cambridge, ed. 1, 27 nov. 2017.

[2] Holmes, C. N. Influence of Environmental Chemicals on Regulatory Processes that Control Glucose and Lipid Homeostasis. 2016. Dissertação (Doutorado em Filosofia) - Faculty of North Carolina State University.

[3] Lima, E.O.; Guerreiro, T.M.; Melo, C.F.O.R.; de Oliveira, D. N.; Machado, D.; Lancellotti, M.; Catharino, R.R. MALDI imaging detects endogenous digoxin in glioblastoma cells infected by Zika virus-Would it be the oncolytic key? Journal of Mass Spectrometry, v. 53, 2018.

[4] Melo, C.F.O.R.; Delafiori, J.; de Oliveira, D.N.; Guerreiro, T.M.; Esteves, C.Z.; Lima, E.O.; Pando-Robles, V.; Catharino, R.R. Serum Metabolic Alterations upon Zika Infection. Frontiers in Microbiology, v. 8, 2017.

Marcucci, H.; Paoletti, L.; Jackwski, S.; Banchio, C. Phosphatidylcholine biosynthesis during neuronal differentiation and its role in cell fate determination. Journal of Biological Chemistry, jun. 2010.

[6] Geng, F.; Cheng, X.; Wu, X.; Yoo, J.Y.; Cheng, C.; Guo, J.Y.; Mo, X.; Ru, P.; Hurwitz, B.; Kim, S.; Otero, J.; Puduvalli, V.; Lefai, E.; Ma, J.; Nakano, I.; Horbinski, C.; Kaur, B.; Chakravarti, A.; Guo, D. Inhibition of SOAT1 Suppresses Glioblastoma Growth via Blocking SREBP-1-Mediated Lipogenesis. Clinical Cancer Research, v. 22, 2016. 